\title{
A More General Non-expected Utility Model as an Explanation of Gambling Outcomes for Individuals and Markets
}

\author{
By David PeEL $\dagger$ and David LAw $\ddagger$ \\ $\dagger$ Lancaster University and $\quad \ddagger$ University of Wales Bangor
}

Final version received 14 May 2008.

\begin{abstract}
One feature of experimental work is the heterogeneity in risk attitudes and probability distortion displayed by agents. We outline a more general non-expected utility model, which nests the models of Markowitz, and Kahneman and Tversky. The model can generate the standard favourite-longshot bias or a reverse favourite-longshot bias as a result of optimal behaviour. We also provide new empirical evidence on the relationship between Tote and bookmaker returns and confirm that the relationship is not as originally conjectured by Gabriel and Marsden. We outline how our new model can provide an explanation of the relationship that is observed.
\end{abstract}

\section{INTRODUCTION}

The great majority of people gamble at actuarially unfavourable odds at least occasionally $^{1}$ and many with relatively large stakes. ${ }^{2}$ These stylized facts are not explained by the standard expected utility model. ${ }^{3}$ A number of authors have attempted to reconcile this apparent contradiction. One increasingly popular approach is to suggest that, although agents are risk averse, they desire the positive skewness of actuarially unfair gambles. ${ }^{4}$ However, this argument cannot apply to expected utility maximizers, as pointed out initially by Brockett and Garvin (1998) and also by Cain and Peel (2004).

An alternative explanation for gambling, in an otherwise standard expected utility model, is to add a non-pecuniary motive (such as excitement or entertainment) that compensates for the expected negative pecuniary returns. See, for example, Clotfelter and Cook (1989) and Farrell and Walker (1999). Whilst it is undoubtedly the case that nonpecuniary returns are relevant for some who engage in gambling, the hypothesis per se is unattractive, because it is inconsistent with a priori reasoning, ${ }^{5}$ with the fact that a majority say they gamble to make money ${ }^{6}$ and with other experimental evidence. ${ }^{7}$

In the context of the expected utility framework, one economic explanation for gambling is that gamblers are risk-loving over their allocation of monies for gambling ${ }^{8}$ (see Ali 1977; Quandt 1986; Weitzman 1965). Whilst the assumption of risk-loving behaviour can explain outcomes such as the favourite-longshot bias observed in UK and US horseracing (see Sauer 1998; Vaughan-Williams 1999, for comprehensive surveys), it is inconsistent with other gambling outcomes. These include: engaging in repetitive, smallstake wagers; betting on more than one horse in a race; purchasing more than one lottery ticket; a reverse longshot bias observed in some gambling markets; or the Tote starting price anomaly of Gabriel and Marsden (1990) (see, for example, Coleman 2004; Hirshleifer 1966; Markowitz 1952; Walls and Busche 2002; Woodland and Woodland 1994).

Whilst it would appear that agents act as risk-seeking when they gamble on longshots at actuarially unfair odds, this behaviour ought to be a predictable outcome of models that are also capable of explaining the other gambling outcomes mentioned above. In addition, the model ought to be able to explain the purchase of insurance as well as such experimental evidence as the Allais paradox or the loss aversion exhibited. 
One feature of experimental work is the heterogeneity in risk attitudes displayed (see, for example, Andersen et al. 2005; Harrison et al. 2007; Hartog et al. 2002; Holt and Laury 2002). As a consequence, Harrison et al. (2007) suggest that one should not readily assume homogenous risk preferences for the population. In a similar vein, the degree of probability distortion observed in an individual would appear, a priori, to differ considerably across individuals given, for instance, the vastly different majority responses to Allais paradox questions (see, for example, Allais 1953; Conlisk 1979; Tversky and Kahneman 1992). Consistent with these observations is the wide dispersion of the reported estimates in experiments where Cumulative Prospect Theory (CPT) is assumed and the Tversky and Kahneman parametric version is estimated. For example, the probability distortion parameter, $\delta$, and the exponent of the power value function over gains, $n$, have reported point estimates of $\delta=0.61, n=0.88$ (Tversky and Kahneman 1992), $\delta=0.56, n=0.225$ (Camerer and Ho 1994), $\delta=0.71, n=0.5$ (Wu and Gonzalez 1996), $\delta=0.98$ or $1.0, n=0.05$ (Bernstein et al. 1997) and $\delta=0.96, n=0.19$ (Stott 2006).

Our purpose in this paper is to show how a model, which borrows from both of the non-expected utility models of Markowitz (1952), Kahneman and Tversky (1979) and Tversky and Kahneman (1992) and which therefore gives an explicit role to both heterogeneity of risk preferences and probability distortion, can provide a coherent explanation of optimal gambling on both favourites or longshots at actuarially unfair odds. We also show how the model can explain how optimal gambling by agents can exhibit the standard favourite-longshot bias or a reverse favourite-longshot bias. We suggest that the differing shape of the bias observed in different countries or different gambling markets might reflect the fact that agents gambling in those markets or countries exhibit different risk characteristics or degrees of probability distortion.

In addition, the model points to an explanation of the relationship observed for winning bets, between Tote returns and bookmaker returns in horseracing. In an innovative paper, Gabriel and Marsden (1990) compared the returns to winning bets in the pari-mutuel pools to those obtained in the parallel bookmaker market. They reported that pari-mutuel returns exceed the returns from bookmakers (at final odds) in the UK, and on this basis concluded that the bookmaker market is not efficient. As Sauer (1998) notes, this result calls for explanation. In fact, subsequent work to that of Gabriel and Marsden has suggested that the relationship is more complex (see, for example, Cain et al. 2001; Pierson and Blackburn 2003). Tote returns appear to exceed bookmaker returns on longer-priced horses and vice versa on favourites. Using a much bigger and new data set than in previous analyses, we report empirical evidence that confirms this more complex relationship. The pattern of data is seemingly not explicable by the CPT model but can be explained by our model.

The rest of the paper is structured as follows. In the next section we set out our new model and show how it is consistent with optimal gambling on favourites and longshots, as well as any shape of the favourite-longshot bias. We then show how our model can also explain the relationship between Tote and bookmaker returns. The paper ends with a brief conclusion.

\section{A General Non-EXPeCted UtiLity Framework}

In a seminal paper, Markowitz (1952) proposed a new model of utility. He assumed that, from an agent's customary or normal level of wealth, the agent is initially risk-loving then 
risk-averse over gains, whilst initially risk-averse then risk-seeking over losses. In addition, Markowitz assumed that the typical agent is loss-averse. Markowitz wrote, 'Generally people avoid symmetric bets. This suggests that the curve falls faster to the left of the origin than it rises to the right. We may assume that $U(-X)>U(X), X>0$ where $X=0$ is customary wealth' (1952: 154-55). However, he also noted that small symmetric bets are sometimes observed and suggested that, for very small symmetric bets, the loss in utility from the bet is both negligible and compensated by the 'fun of participation' (p. 157).

The Markowitz model can explain gambling and insurance, as well as a variety of experimental evidence not consistent with standard expected utility theory. It cannot explain the Allais paradox (Allais 1953). It is well known that in order to resolve this paradox, ceteris paribus, it is necessary to assume that an agent's subjective probabilities differ from objective probabilities and Markowitz assumed them to be equal. ${ }^{9}$

CPT of Kahneman and Tversky (1979) and Tversky and Kahneman (1992) embodies the reference point hypothesis of Markowitz but restricts preferences to be solely riskaverse over gains and solely risk-loving over losses. In CPT, loss aversion is also assumed; however it is of a higher order of magnitude over small stakes than that which Markowitz assumed. To explain both the Allais paradox and gambling on actuarially unfair outcomes, Tversky and Kahneman assume that agents subjectively distort the probabilities of events, via an inverted s-shaped probability weighting function, so that low probabilities are over-estimated and high probabilities are under-estimated.

Empirical evidence on the appropriate shape of the value function suggests it varies across agents (see, for example, Levy and Levy 2001, 2002; Pennings and Smidts 2000, 2003; Smidts 1997). For our purposes we assume that some agents exhibit the form of the value function hypothesized by Markowitz and others that of Tversky and Kahneman. In accord with experimental evidence, we similarly assume that agents can exhibit differences in the degree and type of probability distortion. Defining reference point utility as zero, expected utility, $E u$, is give by

$$
E u=w(p) U^{g}(s o)-w(1-p) U^{1}(s)
$$

where $p$ is the objective probability, $o$ are the odds and $s$ is the stake. $U^{g}(s o)$ is the value derived from a winning gamble, $U(s)$ is the disutility derived from a losing gamble and $w^{+}(p)$ and $w^{-}(1-p)$ are the respective weighting functions over gains and losses. When $w^{+}(p)=p$ and $w^{-}(1-p)=1-p$, there is no probability distortion.

A nice parametric specification that nests the Markowitz and Tversky and Kahneman specifications of the value function is delivered by the expo-power function of Saha (1993). Substitution of that function in (1) gives us

$$
E u=w^{+}(p)\left(1-\mathrm{e}^{-r \lambda(s o)^{n}}\right)-w^{-}(1-p) k\left(1-\mathrm{e}^{-\lambda s^{n}}\right)
$$

where $r, \lambda, n$ and $k$ are positive constants.

With $n \leqslant 1$, the agent is risk-averse over gains and risk-loving over losses, as hypothesized by Tversky and Kahneman. With $n>1$, we obtain the form of value function hypothesized by Markowitz. The agent is initially risk-loving then risk-averse over gains, as $(n-1) / r \lambda n$ is either greater or less than $(s o)^{n}$; and initially risk-averse then risk-loving over losses, as $(n-1) / \lambda n$ is greater or less than $S^{n}$.

The two value functions are shown in Figures 1 and 2. The expo-power function nests the power value function specification of Tversky and Kahneman as $\lambda \rightarrow 0$ (by L'Hopital's Rule) but resolves a number of theoretical and empirical objections to power 


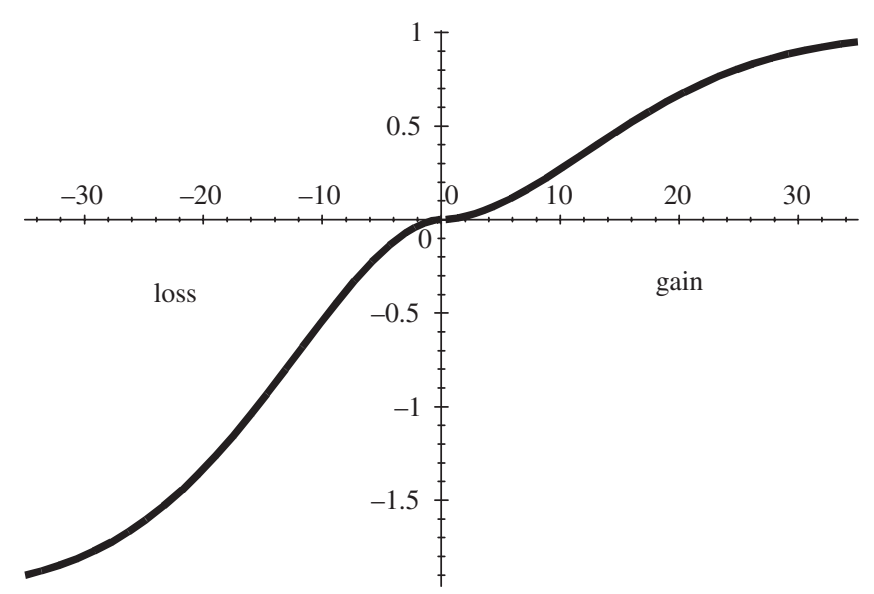

FIGURE 1. Markowitz value function.

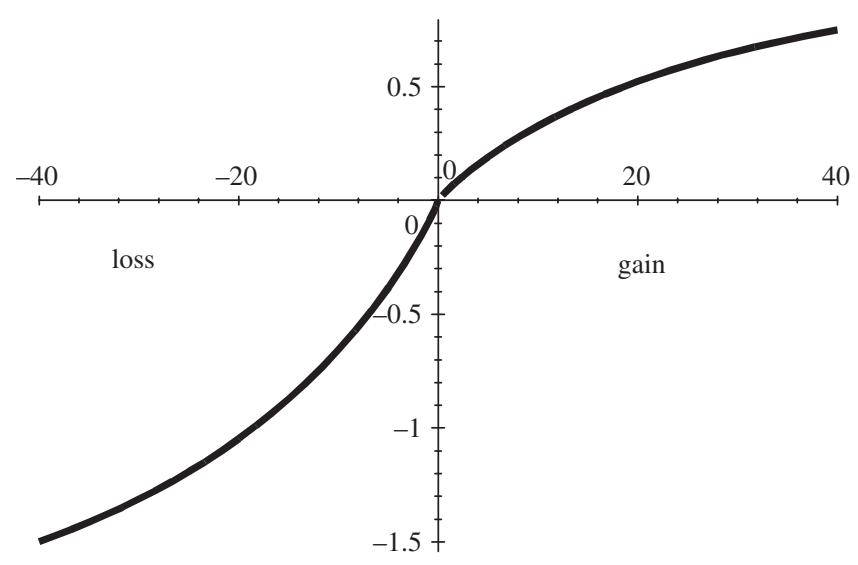

FIGURE 2. Kahneman and Tversky value function.

value functions. ${ }^{10}$ In different applications of CPT to that of gambling, Köbberling and Wakker (2005) and De Giorgi and Hens (2006) also suggest that a bounded value function is more appropriate than a power specification. We assume in our examples that the probability weighting functions over gains and losses, $w^{+}(p)$ and $w^{-}(1-p)$, have the form suggested by Prelec (1998), ${ }^{11}$ which are given by

$$
w^{+}(p)=\mathrm{e}^{-\alpha(-\log p)^{\beta}} \text { and } w^{-}(1-p)=\mathrm{e}^{-\alpha^{1}(-\log (1-p))^{\beta^{1}}}
$$

where $\alpha, \alpha^{1}, \beta$ and $\beta^{1}$ are positive constants.

The degree of loss aversion $(L A)$ is defined by the ratio of the utility gain to the utility loss from a symmetric gamble of stake size, $s$, and is given by

$$
L A=\frac{\left(1-\mathrm{e}^{-r \lambda s^{n}}\right)}{k\left(1-\mathrm{e}^{-\lambda s^{n}}\right)}
$$

As stake size approaches zero, the degree of loss aversion from (4) is given by $r / k$ (by L'Hopital's Rule) and as it becomes large by $1 / k$. In consequence, loss aversion requires 
$1 / k<r / k<1$. It is also necessary to ensure that $\partial L A / \partial s \leqslant 0$, in order that the degree of loss aversion does not vary inversely with stake size. Therefore, we require that $\partial U^{g}(s) / \partial s<\partial U^{1}(s) / \partial s$ for all $s$. This condition is consistent with the definition of loss aversion of Benartzi and Thaler (1995) and Köbberling and Wakker (2005). For the expo-power function, the condition $\partial L A / \partial s \leqslant 0$ implies the additional requirement that $r \geqslant 1$.

Differentiation of (2) with respect to stake size gives us the optimal stake size, $s$, as

$$
s=\left[\frac{\ln \frac{w^{+}(p) r o^{n}}{w^{-}(1-p) k}}{\lambda\left(r o^{n}-1\right)}\right]^{1 / n}
$$

with the second order condition obtained as

$$
r o^{n}-1>0
$$

From the numerator of (5), a necessary condition for optimal stake size to be positive is

$$
\frac{w^{+}(p) r o^{n}}{w^{-}(1-p) k}>1
$$

From (7), we observe the unsurprising features that: (1) that the less loss-averse an agent over small stake gambles, so the larger $r / k$, the more likely, ceteris paribus, the agent is to gamble; and (2) that a differential probability distortion over gains and losses can enhance the attractiveness of gambling by raising the distorted probability ratio $w^{+}(p) / w^{-}(1-p)$ relative to the undistorted ratio $p /(1-p)$ and hence increasing the numerator in (5).

We can define the expected return $(\mu)$ from a one-unit stake gamble as

$$
\mu=p o-(1-p)
$$

so that for an actuarially unfair gamble

$$
\frac{\mu}{(1-p)}+1=\frac{p o}{1-p}<1
$$

From (9) and (7), in the absence of probability distortion, a necessary condition to optimally stake on an actuarially unfair symmetric bet is that the agent is gain-loving so that $r / k>1$. As noted above, Markowitz explicitly acknowledged this possibility. In the context of CPT, it is possible that some agents could exhibit probability distortion where they overestimate large probabilities and underestimate low probabilities. ${ }^{12}$

Inspection of (7) also reveals the not well-appreciated fact that, if $n$ is sufficiently small, ${ }^{13}$ agents optimally gamble at odds on, when odds are actuarially unfair, ceteris paribus. As $n$ becomes smaller, agents become more risk-averse over gains and more risk-loving over losses. This enhances the attractiveness of odds-on gambles. To illustrate, suppose there is no probability distortion, so $\alpha, \alpha^{1}, \beta$ and $\beta^{1}=1$ and also $r=25, k=50$ and $n=0.25$. (Note: there is nothing special about these parameters.) To illustrate, we set $\mu=-0.05263$, which is the expected return to a one-unit gamble at roulette. Figure 3 shows the relationship between expected utility and the objective win probability, when stake size is optimal and given by (5). We observe from the plot that expected utility is positive and approximately at a maximum around $p=0.93$. When playing roulette, this agent would be happiest when betting 35 of the 36 numbers, with an objective win probability of $p=35 / 38=0.92105$. 


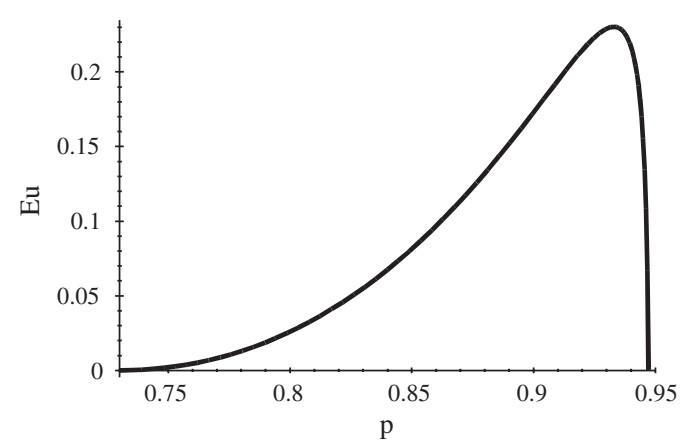

FIGURE 3. Optimally betting odds on in Tversky and Kahneman.

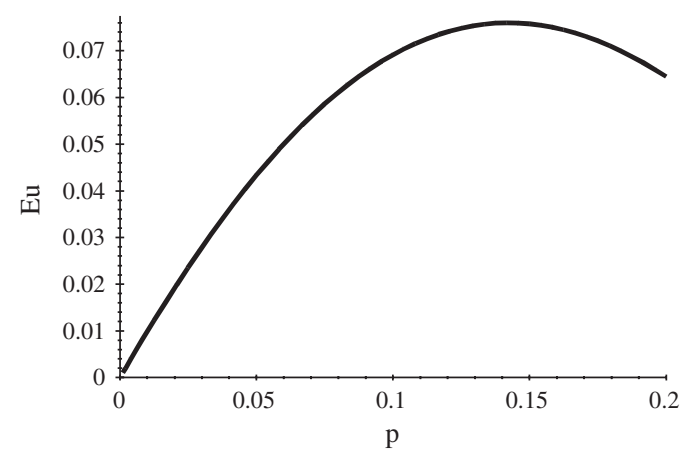

FIGURE 4. Optimally betting on a longshot in Tversky and Kahneman.

The implication that agents in CPT optimally gamble on odds-on favourites, if the degree of risk-aversion over gains and risk-seeking over losses is sufficiently large, is of more than theoretical interest. In practice, agents gamble on odds-on favourites where, by construction, most money is bet, and the standard parametric version of CPT does not explain this. It is also of interest that, as set out above, many experimental studies report estimates of probability distortion parameters and power exponents that are inconsistent with gambling on longshots ${ }^{14}$ but which are consistent with gambling on odds-on favourites.

Figure 4 shows the relationship between expected utility against the objective win probability when $\mu=-0.5$, stake size is optimal, $\alpha=1, \alpha^{1}=1, \beta=0.61, \beta^{1}=0.69$, $r=25, k=50$ and $n=0.88$. These are the parameter values suggested by the Tversky and Kahneman experiments when $\lambda$ is small. The values of the probability distortion parameters imply that low objective probabilities are upward biased and high probabilities downward biased. In consequence, Figure 4 shows the agent optimally betting on an extreme longshot at very unfavourable odds. This is the type of gambling behaviour discussed by Tversky and Kahneman.

In Figure 5, the relationship between expected utility and the objective win probability is shown, when $\mu=-0.5$, the stake size is optimal, and where there is no probability distortion, so that $\alpha=1, \alpha^{1}=1, \beta=1, \beta^{1}=1, r=25, k=50$ and $n=1.5$. This is the type of agent envisaged by Markowitz. The figure shows the agent optimally betting on an extreme longshot at very unfavourable odds. Although the Markowitz utility function exhibits loss aversion of at least two degrees, agents will optimally gamble on longshots even though they do not exhibit probability distortion. 


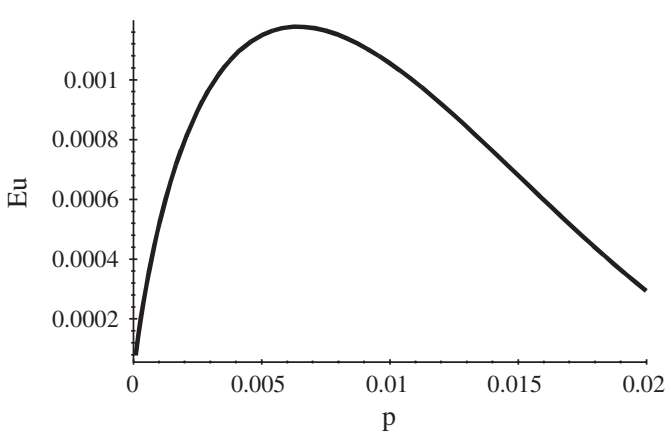

FIGURE 5. Optimally betting on a longshot in Markowitz.

\section{A Model of the Favourite-Longshot Bias}

Our purpose in this section is to show that an optimal gamble produces an outcome with either the standard or reverse favourite-longshot bias. To illustrate, we consider two types of agent, whose value functions differ in shape but where, for simplicity, we assume no probability distortion for either agent. ${ }^{15}$ (Naturally, probability distortion can be readily introduced and is, of course, necessary to explain the Allais paradox.)

Agent 1 has a value function of the form envisaged by Tversky and Kahneman and which is given by the expo-power function with parameters $n=0.4, r=25, k=50, \lambda=0.0024093$. Agent 2 has a value function of the form envisaged by Markowitz and which is given by the expo-power function with parameters $n=1.60, r=25, k=50, \lambda=0.00032459$.

We assume a two-horse race. The objective win probabilities are $p=0.92$ and $1-p=0.08$. The known odds are, respectively, $o_{1}=0.025 / 1$ and $o_{2}=8.225 / 1$. The 'Tote' in this example has a track take of $t=0.0775$. We compute from (5) the optimal stakes of the two agents as: $s_{1}=9$ and $s_{2}=1$. These generate expected utility for agent 1 of $E u_{1}=0.034212$ and for agent 2 of $E u_{2}=0.0019088$. The respective subjective expected probabilities are

$$
0.9=\frac{s_{1}}{s_{1}+s_{2}} \text { and } 0.1=\frac{s_{2}}{s_{1}+s_{2}} .
$$

(Note: $o_{1}=(1-t)\left(s_{1}+s_{2}\right) / s_{1}-1, o_{2}=(1-t)\left(s_{1}+s_{2}\right) / s_{2}-1$.) In this example each agent stakes an optimal amount given the odds and win probability and we observe a standard favourite-longshot bias. The favourite is under bet and the outsider over bet with objective expected returns per 1 unit stake of

$$
\mu_{1}=0.92 \times 0.025-0.08=-0.057 \text { and } \mu_{2}=0.08 \times 8.225-0.92=-0.262 .
$$

In our next example the 'Tote' has a track take of $t=0.06$. We again assume a two-horse race. The objective win probabilities are $p=0.875$ and $1-p=0.125$. The known odds are $o_{1}=0.068182 / 1$ and $o_{2}=6.8333 / 1$. Agent 1 has a value function as envisaged by Tversky and Kahneman, which is given by the expo-power function with parameters $n=0.45, r=25, k=50, \lambda=0.0025722$. Agent 2 has a value function as envisaged by Markowitz, which is given by the expo-power function with parameters $n=1.4, r=25$, $k=50, \lambda=0.00010852$.

From (5), the optimal stakes of the two agents are $s_{1}=8.8$ and $s_{2}=1.2$. This generates expected utility for agent 1 of $E u_{1}=0.000958$ and for agent 2 of $E u_{2}=0.00016$. The respective subjective expected probabilities are $0.88=s_{1} / s_{1}+s_{2}$ and $0.12=s_{2} / s_{1}+s_{2}$. (Note: $o_{1}=(1-t)\left(s_{1}+s_{2}\right) / s_{1}-1, o_{2}=(1-t)\left(s_{1}+s_{2}\right) / s_{2}-1$.) 
In this example each agent stakes an optimal amount and we observe a reverse favourite-longshot bias. The favourite is over bet and the outsider under bet, with objective expected returns per 1 unit stake of

$$
\begin{aligned}
\mu_{1} & =0.875 \times 0.068182-0.125=-0.065341 \text { and } \mu_{2}=0.125 \times 6.8333-0.875 \\
& =-0.020838
\end{aligned}
$$

This model demonstrates how agents with different attitudes towards risk, and more generally differing degrees of probability distortion, can optimally engage in gambling at actuarially unfair odds and that the outcome can exhibit a favourite-longshot bias of either sign.

Empirical results indicate that the favourite-longshot bias observed in UK and US horseracing markets is not universal (see, for example, Busche and Hall 1988; Gandar et al. 2001; Walls and Busche 2002; Woodland and Woodland 1994). Our hybrid model suggests how differences in the parameters of the value function or in the probability weights will cause agents to exhibit 'difference of opinion' and create scope for a betting market in which any aggregate favourite-longshot bias is possible. ${ }^{16}$

We stress that the Markowitz model cannot explain the Allais paradox without introducing probability distortion. We now outline new empirical evidence that is seemingly inconsistent with the CPT model. Reconciliation of both types of evidence requires our more general specification of non-expected utility.

\section{THE TOTE-SP RELATIONSHIP}

In an innovative analysis, Gabriel and Marsden (1990) compared the returns to winning bets in the British Tote with those offered by bookmakers at starting prices. They reported the striking finding that Tote returns to winning bets during the 1978 British horseracing season were higher, on average, than those offered by bookmakers. However, it appears from subsequent work (though on small data sets) that the relationship between Tote returns and bookmaker returns for winning gambles is more complicated than reported by Gabriel and Marsden. Tote payouts for a unit stake appear higher than bookmakers' for longshot winners, with the reverse apparently the case for favoured horses. See Pierson and Blackburn (2003) for the 1993 season and Cain et al. (2001) for the 1978 season.

We re-examine the relationship employing a much larger data set of 46,847 observations ${ }^{17}$ for the seasons 1996-2006. A least-squares regression of the net return to a one-pound bet with the Tote and bookmakers (SP) gave

$$
\begin{aligned}
& \text { Tote }=\underset{(0.11)}{0.99}+\underset{(0.0179)}{1.30 \mathrm{SP}} \\
& \bar{R}^{2}=0.738 ; \mathrm{JB}=0.00 ; \text { White }=0.00
\end{aligned}
$$

Where White heteroscedastic adjusted standard errors are in parenthesis, JB denotes the $p$-value of the Jarque-Bera test for normality of residuals and White denotes the $p$-value of the White heteroscedasticity test of regression residuals. ${ }^{18}$ The hypothesis of equality of expected returns in the two betting media (that is, estimated intercept $=0$, estimated slope $=1$ ) is clearly rejected. In addition, the regression coefficients are indicative of a switch point, above which Tote returns exceed SP and vice versa. Table 1 gives some descriptive statistics for returns to wining Tote and bookmaker odds at various SP. The 
TABLE 1

Returns to Tote And SP AT Various SP: 1996-2006

\begin{tabular}{lccccc}
\hline SP & Winners & Mean Tote & Median Tote & Max. Tote & Min. Tote \\
\hline 0.5 & 187 & 0.487 & 0.5 & 1 & 0.2 \\
0.67 & 315 & 0.637 & 0.6 & 1.1 & 0.2 \\
0.8 & 358 & 0.763 & 0.8 & 1.5 & 0.1 \\
1.0 & 519 & 0.925 & 0.9 & 2.2 & 0.3 \\
2 & 1319 & 1.89 & 1.9 & 4.3 & 0.1 \\
4 & 2437 & 3.93 & 3.9 & 14.9 & 0.8 \\
5 & 2365 & 5.1 & 5.13 & 12.8 & 0.8 \\
10 & 2105 & 11.4 & 11 & 34.1 & 3.7 \\
20 & 1284 & 26.66 & 24.6 & 179 & 4.9 \\
33 & 587 & 45.7 & 41 & 260.2 & 8.5 \\
\hline
\end{tabular}

data show that for this larger data set, Tote returns are on average higher for SP $>5$ and vice versa. These results confirm those suggested by earlier studies, which were subsequent to that of Gabriel and Marsden. As stressed by Cain et al. (2003), an explanation for this finding must recognize that bets on the Tote have uncertain payoffs whilst those with bookmakers are essentially certain. Whilst bettors have some information on the pattern of on-course betting via Tote boards, off-course bettors have no such information and the payout is determined after the race by the total amount bet.

\section{CPT AND THE MODIFIED TOTE-SP RELATIONSHIP}

It would appear that the nature of the relationship between Tote and SP returns is problematic for the CPT model. To illustrate this point, consider a bet of size $s$ on the Tote or SP. The probability of the horse winning is the same for either bet so that the value function for losses is the same for either bet. As a consequence, the choice between the two betting mediums is determined by the expected value of the certain SP return relative to the expected value of the uncertain Tote return.

Jensen's inequality implies, where $G$ is the gain and $E G$ the expected gain, that

$$
E U(G)>U(E G), E U(G)=U(E G) \text { and }<U(E G)
$$

when the agent is, respectively, risk-loving, risk-neutral and risk-averse over gains. In consequence, as pointed out by Cain et al. (2003), expected returns would be expected to be equal on average only if the representative punter is risk-neutral. Moreover, in CPT, where agents are assumed risk-averse everywhere over gains, ex-ante an agent must expect a higher return from betting on the Tote, on either favourites or longshots, to compensate for the risk. This expectation is inconsistent with the new empirical results. On the other hand, as Cain et al. (2003) indicate, the Markowitz model, because of the assumed risk-seeking behaviour over favourites and risk-averse behaviour over longshots, implies that an agent could optimally bet on the Tote mindful of the empirical relationship between Tote and SP returns. 


\section{CONCLUSION}

Experimental evidence suggests that agents exhibit great heterogeneity over riskpreferences and degrees of probability distortion. We have set out a more general nonexpected utility model that nests those of Kahneman and Tversky and Markowitz, and thus permits more heterogeneity. We have shown how this model might provide an explanation of a variety of gambling outcomes (as well as experimental outcomes), some of which are not reconcilable with either CPT or the Markowitz model.

In particular, we showed why some agents might optimally gamble on longshots and others on favourites at actuarially unfair odds without invoking extraneous factors such as entertainment. ${ }^{19}$ We have also shown how differences in attitude to risk might generate a favourite-longshot or reverse favourite-longshot bias as an outcome of optimal betting by individuals. Given the conflicting empirical evidence for the shape of the bias in different countries or gambling markets, this type of model seems of relevance in explaining the different aggregate biases observed in different countries and sports.

We confirmed the more tentative findings of earlier studies, that the relationship between winning Tote and SP is not as originally envisaged by Gabriel and Marsden. In particular, Tote returns exceed bookmaker returns on longshots and vice versa. Because Tote returns are uncertain whilst bookmaker returns are essentially known, Jensen's inequality shows that an agent, who is risk-averse (risk-loving) over gains, expects a higher (lower) return from the Tote than from the bookmaker. Consequently, the empirical result appears difficult to reconcile with the CPT model. On the other hand, the Markowitz model appears consistent with this empirical finding. However, the Markowitz model cannot explain the Allais paradox, which of course CPT can, and for these reasons we require the more general model to explain both sets of outcomes.

The more general non-expected utility model we propose can replicate the great heterogeneity in preferences and probability distortion displayed by agents in experimental work. This feature allows us to provide an explanation of optimal gambling by individuals, which does not require appeal to entertainment, skewness or everywhere risk-seeking preferences over gambles. The model might also help explain aggregate gambling outcomes such as different favourite-longshot biases and the ToteSP relationship.

\section{ACKNOWLEDGMENTS}

We are grateful to D. Paton, G. Steeley and an anonymous referee for helpful comments. Needless to say, remaining errors are our responsibility.

\section{NOTES}

1. For instance, in $199868 \%$ of respondents in the US reported gambling at least once in the previous year. Legal gambling losses in America totalled over $\$ 50$ billion and illegal gambling has been estimated at over \$100 billion (see, for example, National Research Council 1999; Strumpf 2002).

2. For instance, Bruce and Johnson (1992) report average stakes of $£ 22.63$ on racehorse favourites. Strumpf (2002) reports that average bet size averaged in excess of $\$ 1000$ in a study of six illegal bookmakers.

3. Hence the famous early quotation: 'There is, however, one common observation which tells against the prevalence of risk aversion, namely, that people gamble ... I will not dwell on this point extensively, emulating rather the preacher, who, expounding a subtle theological point to his congregation, frankly stated: "Brethren, here there is a great difficulty; let us face it firmly and pass on"” (Arrow 1965).

4. For instance Golec and Tamarkin (1998: 224) write, 'horse bettors accept low-return, high-variance bets because they enjoy the high skewness offered by these bets' and 'We claim that bettors could be riskaverse and favour positive skewness, and primarily trade off negative expected return and variance for positive skewness.' However, since globally risk-averse agents will not gamble at actuarially unfair odds 
we know the skewness argument is erroneous. The error is to assume that since the third derivative of the utility function is positive for a globally risk-averse agent, a gambler will trade that positive skewness for a lower mean. This is invalid for simple gambles (see Cain and Peel 2004).

5. Friedman and Savage (1948) and Markowitz (1952), in their seminal papers, provide a critique of the entertainment rationale. For instance, Markowitz notes that if the utility of a gamble is the expected utility of the outcomes plus the utility of playing the game, then, for given fair odds, the smaller the amount bet, the higher the expected utility. This implies millionaires should play poker for pennies and no one should purchase more than one lottery ticket.

6. When surveys ask gamblers why they gamble, a majority (approximately $42-70 \%$ ) cite financial reasons: 'to make money' (see, for example, The Wager 2000). Bruce and Johnson (1992) examined the pattern of betting before the off, for 1200 bets on horse races: 'the most striking conclusion relates to the unambiguous confirmation of the existence of a subset motivated by financial returns.'

7. Many experimental results conflict with the standard expected utility model. An excellent discussion of this experimental evidence can be found in Starmer (2000). These results include the famous Allais paradox, where probability distortion is necessary to explain the results (see Allais 1953; Tversky and Kahneman 1992).

8. Although the Friedman and Savage (1948) specification of expected utility - with an initial risk-averse then risk-loving then risk-averse segment - can explain both gambling and insurance, there are a number of crucial implications that run counter to observed facts. See, for example, Markowitz (1952).

9. See Peel et al. (2008) for an analysis of the Markowitz model embodying probability distortion.

10. Using small real payoffs, Holt and Laury (2002) find that risk aversion increases sharply as payoffs are increased and agents choose between a 'safer' and 'more risky' gamble. With a power value function this would not occur. This result is consistent with early experimental evidence, for example Markowitz (1952) and Binswanger (1980). There are also important theoretical objections to the power assumption. See, for example, Cain et al. (2008).

11. The form suggested by Prelec (1998) is more flexible than that assumed by Tversky and Kahneman, which is given by $w^{+}(p)=p^{\delta} /\left[p^{\delta}+(1-p)^{\delta}\right]^{\frac{1}{\delta}}, \delta=$ constant over gains. For instance, the subjective probability cannot exceed 0.5 , when $p=0.5$, which is necessary to explain the risk-seeking behaviour obtained in some experiments. For example, Battalio et al. (1990) report experiments in which agents prefer the gamble to its certainty equivalent. This outcome is inexplicable with the Tversky and Kahneman parametric specification.

12. Consistent with the experimental evidence in Battalio et al. (1990).

13. This possibility is noted in Peel and Law (2007) and Cain et al. (2008). Cain et al. also note that, in bounded CPT models, an agent might obtain positive utility with very large scale gambles at odds on, since as stake size goes to infinity expected utility will be positive. For instance, $w^{+}(p) / w^{-}(1-p)>k$ in the case of the expo-power value function.

14. Cain et al. (2008) show that a necessary condition for betting on longshots is that the elasticity of the weighting functions over gains has to be less than the elasticity of the value function over gains.

15. An important explanation of the bias is that of Shin $(1991,1992,1993)$ and Hurley and McDonough (1995). They analyse models where informed and uninformed agents interact with different assumptions concerning the information of the informed and uninformed agents. However no utility framework is provided for the betting behaviour of the uninformed agents and the informed agents are assumed riskneutral. It would seem possible to introduce informed agents into the model we set out. However our model does not require this feature to explain any pattern of bias.

16. A possibility for future work suggested by a referee is a simulation exercise in which the parameters are chosen from a multivariate distribution for many bettors and the aggregate outcome explored.

17. Kindly provided by flatstats.co.uk.

18. Given the severe non-normality and heteroscedasticity of the residuals, we also employed the wild bootstrap to obtain critical values of the white adjusted standard errors. These were near identical to those reported (see, for example, Davidson and Flachaire 2001).

19. Even though one can agree that the entertainment motive may be relevant for agents gambling with small stakes.

\section{REFERENCES}

Ali, M. M. (1977). Probability and utility estimates for racetrack bettors. Journal of Political Economy, 85, $803-15$.

Allais, M. (1953). Le Comportement de l'Homme Rationnel devant le Risque: Critique des Postulats et Axiomes de l'Ecole Américaine. Econometrica, 21, 503-46.

Andersen, S., Harrison, G. W., Lau, M. I. and Elisabet Rutström, E. (2005). Preference heterogeneity in experiments: comparing the field and lab, mimeo University of Durham.

Arrow, K. J. (1965). The theory of risk aversion. In K. J. Arrow, Aspects of the Theory of Risk-bearing. Helsinki: Yrjo Jahnssonin saatio. 
Battalio, R. C., Kagel, J. C. and JiRAnyakul, K. (1990). Testing between alternative models of choice under uncertainty: some initial results. Journal of Risk and Uncertainty, 3, 25-50.

Benartzi, S. and Thaler, R. H. (1995). Myopic loss aversion and the equity premium puzzle. Quarterly Journal of Economics, 110, 73-92.

Bernstein, L. M., Chapman, G., Christensen, C. and Elstein, A. S. (1997). Models of choice between multioutcome lotteries. Journal of Behavioral Decision Making, 10, 93-115.

Binswanger, H. P. (1980). Attitude toward risk: experimental measurement in rural India. Journal of Agricultural Economics, 62, 395-407.

Brockett, P. L. and GARVen, J. R. (1998). A re-examination of the relationship between preference and moment orderings by rational risk averse investors. Geneva Papers on Risk and Insurance Theory, 23, 127-37.

Bruce, A. C. and Johnson, J. E. V. (1992). Toward an explanation of betting as a leisure pursuit. Leisure Studies, 11, 201-18.

Busche, K. and Hall, C. D. (1988). An exception to the risk preference anomaly. Journal of Business, 61, $337-46$.

CAIN, M. and PeEL, D. (2004). Utility and the skewness of return in gambling. Geneva Papers on Risk and Insurance Theory, 29 (2), 145-63.

— LAw, D. and PeEL, D. (2001). The incidence of insider trading in betting markets and the Gabriel and Marsden anomaly. The Manchester School, 69, 197-207.

- and (2003). The favourite-longshot bias and the Gabriel and Marsden anomaly: an explanation based on utility theory. In L. Vaughan Williams (ed.), The Economics of Gambling. London: Routledge, pp. 2-13. p. $2-13$.

(2008). Bounded cumulative prospect theory: some implications for gambling outcomes. Applied Economics, 40 (1), 5-15.

CAMERER, C. and Ho, T. H. (1994). Violations of betweeness: axiom and nonlinearity in probability. Journal of Risk and Uncertainty, 8, 167-96.

Clotfelter, C. T. and Cook, P. J. (1989). Selling Hope: State Lotteries in America. Cambridge, MA: Harvard University Press.

Coleman, L. (2004). New light on the longshot bias. Applied Economics, 36, 315-26.

Conlisk, J. (1979). Three variants on the Allais example. American Economic Review, 79 (3), 392-407.

Davidson, R. and Flachaire, E. (2001). The wild bootstrap, tamed at last, mimeo, Department of Economics, Queen's University, Kingston, Ontario.

De Giorgi, E. and Hens, T. (2006). Making prospect theory fit for finance. Financial Markets and Portfolio Management, 20 (3), 339-60.

FARrell, L. and WALKer, I. (1999). The welfare effects of Lotto: evidence from the UK. Journal of Public Economics, 72, 99-120.

Friedman, M. and Savage, L. (1948). The utility analysis of choices involving risk. Journal of Political Economy, 56, 279-304.

Gabriel, P. E. and MARsDen, J. R. (1990). An examination of market efficiency in British racetrack betting. Journal of Political Economy, 98, 874-85.

Gandar, J. M., Zuber, R. A. and Johnson, R. S. (2001). Searching for the favourite longshot bias down under: an examination of the New Zealand parimutuel betting market. Applied Economics, 33, 1621-29.

Golec, J. and TAMARKIN, M. (1998). Bettors love skewness, not risk, at the horse track. Journal of Political Economy, 106, 205-25.

Harrison, G. W., List, J. and Towe, C. (2007). Naturally occurring preferences and exogenous laboratory experiments: a case study of risk aversion. Econometrica, 75 (2), 433-58.

Hartog, J., Carbonell, A. F. I. and Jonker, N. (2002). Linking measured risk aversion to individual characteristics. Kyklos, 55 (1), 3-26.

HirshleIfER, J. (1966). Investment decision under uncertainty: applications of the state-preference approach. Quarterly Journal of Economics, 80, 252-77.

Holt, C. A. and Laury, S. K. (2002). Risk aversion and incentive effects. American Economic Review, 97, $1644-55$.

Hurley, W. and McDonough, L. (1995). A note on the Hayek hypothesis and the favorite-longshot bias in parimutuel betting. American Economic Review, 85 (4), 949-55.

Kahneman, D. and Tversky, A. (1979). Prospect theory: an analysis of decision under risk. Econometrica, 47 (2), 263-91.

KöbBerling, V. and WAKker, P. (2005). An index of loss aversion. Journal of Economic Theory, 122, 119-31.

LEVY, H. and LEVY, M. (2001). Testing for risk aversion: a stochastic dominance approach. Economics Letters, 71, 233-40. 
and - (2002). Prospect theory, much ado about nothing? Management Science, 48, 1334-49.

Markowitz, H. M. (1952). The utility of wealth. Journal of Political Economy, 56, 151-54.

National Research Council (1999). Pathological gambling: a critical review. Committee on the Social and Economic Impact of Pathological Gambling, National Research Council.

PeEL, D. A. and LAw, D. (2007). Betting on odds on favourites as an optimal choice in Cumulative Prospect Theory. Economics Bulletin, 44(26), 1-10.

$\longrightarrow$, ZhANG, J. and LAw, D. (2008). The Markowitz model of utility supplemented with a small degree of probability distortion as an explanation of outcomes of Allais experiments over large and small payoffs and gambling on unlikely outcomes. Applied Economics, 40(1), 17-26.

Penning, J. M. E. and Smidts, A. (2000). Assessing the construct validity of risk attitude. Management Science, 46 (10), 1337-48.

- and (2003). The shape of utility functions and organizational behavior. Management Science, 49, 1251-63.

Pierson, J. and BlackBURn, P. (2003). Betting at British racecourses: a comparison of the efficiency of betting with bookmakers and at the Tote. In L. Vaughan Williams (ed.), The Economics of Gambling. London and New York: Routledge, pp. 30-42.

PRELEC, D. (1998). The probability weighting function. Econometrica, 66, 497-527.

QuANDT, R. E. (1986). Betting and equilibrium. Quarterly Journal of Economics, 101, $201-07$.

SAHA, A. (1993). Expo-power utility: a flexible form for absolute and relative risk aversion. American Journal of Agricultural Economics, 75, 905-13.

SAUER, R. D. (1998). The economics of wagering markets. Journal of Economic Literature, 36, $2021-64$.

SHIN, H. S. (1991). Optimal odds against insider traders. Economic Journal, 101, 1179-85.

(1992). Prices of state contingent claims with insider traders, and the favourite-longshot bias. Economic Journal, 102, 426-35.

(1993). Measuring the incidence of insider trading in a market for state-contingent claims. Economic Journal, 103, pp. 1141-1153.

SmidTs, A. (1997). The relationship between risk attitude and strength of preference: a test of intrinsic risk attitude. Management Science, 43, 357-70.

STARMER, C. (2000). Developments in non-expected utility theory: the hunt for a descriptive theory of choice under risk. Journal of Economic Literature, 38, 332-82.

Sтотт, H. P. (2006). Cumulative prospect theory's functional menagerie. Journal of Risk and Uncertainty, 32, $101-30$.

StrumpF, K. S. (2002). Illegal sports bookmakers, mimeo, University of North Carolina at Chapel Hill.

TVERSKY, A. and KAHNEMAN, D. (1992). Advances in prospect theory: cumulative representation of uncertainty. Journal of Risk and Uncertainty, 5 (4), 297-323.

VAughan Williams, L. (1999). Information efficiency in betting markets: a survey. Bulletin of Economic Research, 51, 307-37.

WALls, W. D. and BuSche, K. (2002). Breakage, turnover and betting market efficiency: new evidence from Japanese horse tracks. In L. Vaughan Williams (ed.), The Economics of Gambling. London: Routledge.

WAGER, THE (2000). Stress, anxiety, and why gamblers gamble. Massachusetts Council on Compulsive Gambling, 27 May.

WeItZMAN, M. (1965). Utility analysis and groups behavior: an empirical study. Journal of Political Economy, 73, $18-26$.

Woodland, B. M. and Woodland, L. M. (1994). Market efficiency and the favorite-longshot bias: the baseball market. Journal of Finance, 49, 269-79.

Wu, G. and Gonzalez, R. (1996). Curvature of the probability weighting function. Management Science, 42 , 1676-88. 